\title{
Voice work at the Royal Shakespeare Company
}

\section{Andrew Wade}

\section{(2) OpenEdition \\ Journals}

Electronic version

URL: http://journals.openedition.org/shakespeare/414

DOI: 10.4000/shakespeare.414

ISSN: 2271-6424

\section{Publisher}

Société Française Shakespeare

\section{Printed version}

Date of publication: 1 November 1999

Number of pages: $209-228$

ISBN: 2-84269-331-0

\section{Electronic reference}

Andrew Wade, "Voice work at the Royal Shakespeare Company ", Actes des congrès de la Société française Shakespeare [Online], 17| 1999, Online since 01 November 2007, connection on 20 April 2019. URL : http://journals.openedition.org/shakespeare/414 ; DOI : 10.4000/shakespeare.414 


\section{S H A K E S P E A R E \\ \& $\quad$ L $A \quad$ V O I X}

Société Française Shakespeare

Actes du Congrès de 1999

米米

Textes réunis et présentés par

Patricia DORVAL

publiés sous la direction de

Jean-Marie MAGUIN 


\section{VOICE WORK AT THE ROYAL S H A K E S PEA RE COM PANY}

Let me say, first of all, how truly delighted I am to be speaking here today, at a conference which $I$ feel is both crucial and extremely well-timed, if I may say so !

But perhaps a small anecdote would express this better...

One day - not so long ago - there was a Hollywood screenwriter called Marc Norman. Some of you here might remember him as the screenwriter for such unforgettable films, as Cutthroat Island (!) or indeed the magnificent (!) Waterworld great classics, deserving some real academic attention, I'm sure...

Anyway, one day this man - Marc Norman - was discussing Romeo and Juliet with his schoolboy son, and perhaps partly to inspire his son he said he felt this was the play in which, to him, Shakespeare «really finds his voice». Spurred on by this, he then went on to write a film script to try and explore why and how Shakespeare found his voice.

But the buck of how Shakespeare «really found his voice» was to be passed on to another man, the playwright Tom Stoppard, who finalised a script which was to bear the somewhat alluring title of Shakespeare in Love - a film I'm sure many of you are now familiar with.

By the time the film was cast and the actors started rehearsing however, Marc Norman's comment to his schoolboy son had become, as you can imagine, a vital concern : how did Shakespeare really find his voice? Is there a Shakespeare voice? Or, 
alternatively, how does one find a Shakespeare voice that speaks to our contemporary audiences? This last question, was the buck that was partly passed on to me and the question that I had to confront, when I was asked to work with the actors. While speaking the words aloud, it became all the more important to release a voice that was not only balanced against Shakespeare and Stoppard's writing, but also one that would speak to the audiences of today.

To end this anecdote, I would like to say that Marc Norman's haunt has been something which we have never ceased to address, for many years now at the RSC. And interestingly, it seems that a socalled truly popular medium, the cinema, appears to be confronting the issue fairly regularly these days as well, this is why I think the question of Shakespeare's voice continues - happily for all of us here today ! - to be an important one.

As Head of the RSC Voice Department, I feel it is also my duty to try and dispel the mystique surrounding the way we, at the RSC, work with actors on their voices. This is why I believe it is equally important for me to throw some light on the history and purpose of voice work at the RSC, which to an extent, should help you understand what we mean when we come to speak of «Shakespeare's voice».

What is indeed the function of a voice person, or of voice work in theatre? Traditionally, one is perhaps more inclined to think of voice work as linked to drama schools. I have no doubt also that there are a certain number of words which spring into your mind almost instinctively when voice is mentioned, some of them no doubt prompted by current controversies about the preservation of what some have called the British theatrical heritage. These are if I may venture a series of guesses - verse speaking, audibility, diction, projection, Received Pronunciation, and perhaps standards of speaking. So many issues seem to be tied up to voice at the moment, issues of cultural, social, intellectual, artistic, or indeed political importance - this, at least, is the impression one might get by reading the recent press.

There is, I think, great need to clarify some of the underlying assumptions behind many of these words, and perhaps it will always be the case ! In order to do so, however, I feel I must clarify the basic question of my being here today, as the mouthpiece of a small group of people who are members of one department - the RSC Voice Department - a title which sounds somewhat institutional. In fact, nothing - even at the RSC ! - is ever fully an institution, as nothing survives for long in theatre that doesn't have a practical role 
to play. I am only speaking before you today because there has been, for many years now, a need for specific voice work which grew at the same time as the company and is now part and parcel of the history of the RSC. It is this growth which I'd like to recount first and foremost. This, I feel, is the best way to address at a later stage in this paper the status and role of voice work at the RSC at present and also in the context of major upheavals in the theatrical world. I will endeavour lastly to shed some light on what I would like to think of as the philosophy behind the work carried out, with actors and directors, on language.

\section{The formation of a department}

Looking back at the history of the Company, one can see that there was clearly a crucial period of time when the character of the RSC was defined with more precision and when the need for voice work became gradually acknowledged.

For me, the beginning of this period is marked symbolically by the arrival in 1960 of Peter Hall as Artistic Director. From then on, the company was shaped by a series of people who each had a strong vision for the company. The repertoire gradually widened to take in modern work and classics other than Shakespeare. Already there was a will to work in parallel on both classical and contemporary text so as to discover and re-invent the ways of reaching modern audiences through language.

There was one idea which, to my mind, dominated the 1960s and the years after - that was the idea of training. Directors such as Peter Hall, Peter Brook, and Michel Saint-Denis believed in the value of experimenting, of not seeking final solutions or concrete theories in theatre. In January 1960, Hall appointed John Barton as Assistant Director of the Memorial Theatre, as many of you already know. He was, at this time, Lay Dean of King's College, Cambridge, and an authority on Elizabethan speech and drama. John Barton led verse-speaking classes. The decisive element was that training was taken as a continuous process, meant for experienced and neophyte actors alike. This is how Peter Hall expressed these views in 1963 :

We believe that a company can only be created if each actor in addition to his main work, is continually developed and reexamined by training in the Studio and by taking part in experiments in public. We want 
to increase this work. ${ }^{1}$

Many of the directors, as well as Peter Hall, had a genuine passion for form and placed strong emphasis on the importance of verse-speaking. Peter Brook was aware of the challenge that this entailed. The same year - 1963 - he wrote :

We must get him [the actor] to see that the challenge of the verse play is that he must bring to it an even deeper search for truth, for truth of emotion, truth of ideas, and truth of character - all quite separate and yet all interwoven - and then as an artist find, with objectivity, the form that gives these meanings life. $^{2}$

One of the ways of exploring this connection between form and meaning was through practical work on theatre's privileged medium of communication, the human voice. The first reference to any technical voice work, led by people who were specialised in voice, was linked to a singing teacher called Denne Gilkes. A pianist and well-known singer, Gilkes also displayed particular skills as a teacher of voice production. Her association with what was to become the Royal Shakespeare Theatre had actually begun in 1936 and continued until her death in 1972. During this period, the large panelled music room of her Stratford-upon-Avon High Street house - where I believe Waterstone's is now - was to become familiar to many actors. Having settled in Stratford after much touring abroad as a singer, she had taken over the post of music teacher for King Edward's High School for Girls in Birmingham. Soon, her talent and particular gift for teaching voice reached the ears of some of the members of the Memorial Theatre company. But the actual link between Denne and the theatre became more firmly established thanks to Anthony Quayle who had taken singing lessons with her in preparation for his Othello in 1954. Actors from then on were to take lessons more regularly at her studio. Her aim was not to turn actors into musicians or singers, but her approach to voice was definitely through singing. Today, at the RSC, the approach has changed: singing teachers are brought specially to deal with the sung voice, while voice coaches deal with the slightly different needs of the spoken voice. Already it had become apparent to her that any work done with the actor had to remain on their terms and serve a practical purpose. Steering clear of dogma, she said, in an interview 
for the Stratford Herald in 1960, «I would never say that I have discovered a method of training, I can only say: 'Here is one way - does it work for you ?'». She also advised that it is «no good just plugging away with technicalities all the time. It is what is in the mind that matters». She believed that the voice should combine with the mind in such a way as to create emotion almost by instinct.

Peter Hall, nevertheless, was the first to employ a voice teacher, Iris Warren, who was invited in as a consultant and led a series of classes on Saturday mornings in the early 1960s. During the rest of the week she continued to give private tuition in London. Warren sometimes led small group calls but most of the work she did for the company was through individual lessons. Patsy Bryne, who joined the company in 1960 on a long-term contract recalls the nature of the work carried out :

I can remember all the exercises... Those for relaxation were most useful - from a position of doubled-up relaxation, she required me to scream and leap in the air. The noise brought the traffic on Waterside to a halt. For breathing exercises she asked us to imagine that our breathing equipment was like an apple (the core, the centre) over which spread a skin (the diaphragm). But, she would say: «Don't forget the pips!» This became the slogan used by us all, in chorus, at moments of levity. ${ }^{3}$

As to her general attitude to voice work Iris Warren would herself point out: «the voice is a human instrument of communication, and I am more concerned with freeing the person into the voice then training it». She is also remembered for her personal approach to teaching: «my main interest is in people, not voices», was one of her favourite statements ${ }^{4}$. Already one senses in these early years, a slight change of direction. Warren was more than a voice teacher. Her work was specifically about understanding people and their artistic needs. This perhaps more «psychological» approach is no longer at the heart of voice work at the RSC, although admittedly it is impossible to separate voice and psyche. Peter Hall, who employed her and recognises that the RSC owes a considerable debt to her, remarks significantly: «I did not find her working enough on the text - more on the sound and timbre of the voice» ${ }^{5}$. He adds : «My memory is certainly that as the style of the RSC with its emphasis on wit, lightness and speed - became more 
defined, Iris's more emotional approach faded away. This came at the same time as her desire not to get lost in the Company». With Iris Warren voice work had gained a measure of recognition in theatre but the voice person remained somewhat of an outsider who consequently had only a limited bearing on the rehearsal process.

Thus, it was not until 1969, when Cicely Berry was invited in by Trevor Nunn (who had replaced Peter Hall as artistic director), that the real foundations of voice work for actors in theatre were laid. Cicely quickly revealed the huge potential of voice work, and the care and energy she put into every production - two qualities which she continues to hold! - was to seal the association between voice and theatre at the RSC. After being only a part time activity, voice soon acquired a full time status. Cicely, in truth, pioneered the role of the voice person working as part of the production team, no longer just opening the voice out and addressing the actors' audibility in the given theatre space, but trying to find a way with the director for actors to connect with words.

What Cicely has striven to establish at the RSC has been regularly balanced against and fed by opportunities outside the company. She's worked with youngsters, teachers, and even in prisons : this type of work provided her with new and different reference points which in turn helped develop approaches to language that informed the work she did and does with actors.

She worked in close association with directors such as Trevor Nunn, John Barton, Terry Hands and Peter Brook, seeking to respond to their varied demands and stimuli in ways which could help actors live up to what was being asked of them during rehearsal. Terry Hands, Cicely recalls, tended to demand more pace and wanted actors to speak to the end of the verse line ; so often, Cicely's work consisted in trying to help the actor discover the energy of word to word that would in the end release the speed, whilst maintaining the specific thinking. Trevor Nunn wanted to devote more attention to the specific relation between words, parts of speeches, he also wanted more naturalism; Cicely thus found that working on the structure of a Shakespeare speech, for example, could be helpful for the actors in that it allowed them to find the relationship through form also. With other directors, who had more of an intellectual approach to meaning, she developed practical ways of freeing actors so as to enable them to reach their own personal connection with the text - taking the sole concentration off the conscious mind, as it were. She helped them find their confidence with the words by encouraging them to create their own imaginative response to the 
language.

Cicely was also directly instrumental in the setting up of what was to become a department. As the company grew, particularly with the expansion of the Swan Theatre, casting needs changed and the work demands resulted in the appointment of an assistant position in Stratford. Bardy Thomas was first hired on a part-time basis. David Carey took over on a full-time basis and a part-time position at the Barbican was given to Patsy Rodenburg. I replaced David in 1988 as Assistant Voice Director.

In the decade I have spent with the Company, the need for voice work has been reaffirmed. This of course has not happened as a matter of pure logic. Again and again voice had to continue proving its relevance and revealing all of its potentialities. But the terrain has continued to be favourable to voice. Adrian Noble succeeded Terry Hands in 1991 . He has striven since to maintain the tradition of studio theatre in Stratford while pioneering in other areas. One of his stated aims - which is widely quoted - is to make the company «the best classical theatre company in the English-speaking world». ${ }^{6}$ Thus, this new policy has included the expansion of the voice profile. I became Head of Department in 1990 with one full-time colleague in London and one in Stratford Barbara Houseman and Lyn Darnley. Cicely Berry remains as Voice Director and this frees her to devote more time to specific projects.

\section{The voice department in the current theatrical context}

As you probably realise - after this rapid sketch of the growth of voice work at the RSC - despite the impression of continuity which you might get, most of what we all do in theatre undergoes a constant process of redefinition, of questioning, as whatever we build has to serve the needs of something that is moving, organic, and ever-changing. This, of course, doesn't mean that I cannot give you a clearer picture of the voice work carried out at the RSC today. Remember however that we have no syllabus, no dogma to impose, no method to put forward, no infallible way of making those actors «speak the speech» properly, or find that hypothetical «Shakespeare voice». What we offer actors is, hopefully, an appropriate way - at this moment in time - to serve their needs and those of the production.

The nature of the voice work carried out currently at the RSC revolves primarily around two areas. First, we deal with the fundamentals of the actors' voices, trying as much as possible to reveal the intimate connections with the body: we work with the 
actors on relaxation, breath, resonance, muscularity of sounds (our vowels and consonants are closely tied up to the movement of specific muscles) and, last but not least, on words, taking into account the different requirements of each theatre auditorium. Secondly, we are concerned with how actors relate to language within the rehearsal process and in performance.

Within the life of the RSC, these two strands are addressed in many ways. Our task consists, primarily, of being in rehearsal, of liaising with directors to keep them informed and to discuss how the work is developing. We then set up calls and work with the actors away from the rehearsal room. These calls can be solus, small group calls, as well as company sessions, which can also take place in the auditorium. During previews and prior to Press Night, it is often essential to organise company calls in the auditorium to help bridge that gap between rehearsal room and theatre.

As the season establishes its repertoire format, there is the opportunity to introduce blocks of classes. Early morning sessions, lunch time verse work, sessions in the different theatre spaces, taking projects out into the community are just a few examples of the possibilities. There is not and should not be a time-table for the work. Inevitably, it has to be playing by ear and responding to the needs as they arise.

To give an even more detailed account of the on-going work, our role involves leading warm-ups before performances, setting up solo sessions with actors, working with understudies, and monitoring performances. The same attention is devoted to the actors when on tour or when the on-going work is transferring from one venue to the other. Voice care is not the least of our concerns either : we have Ear, Nose and Throat consultants, voice therapy links, voice care talks and advice.

Whatever the area, we as voice people at the RSC owe a total commitment to the actors and have a constant responsibility towards the language. The underlying idea behind the work we do with actors is that we allow them to explore without limitation, while never overlooking the demands of the production.

One is also quickly reminded that the RSC operates within the theatrical culture as a whole and that the voice work carried out within the organisation responds to and reflects the actors who work there. They themselves are a product of the theatre climate and of the training in Britain. The climate is more fluid than it has been for a very long time as the traditional training establishments are being forced to restructure. 
The RSC, in many ways, could be seen as an island in an ocean of generalism. As we all know, an actor today is expected to be incredibly versatile. Consequently, drama schools are torn as to what aspect or for which type of theatre they are preparing their actors. The result is that voice work is having to cater for an actor who is possibly going to work in film, television, radio, theatre, schools, restaurants, outside and inside, with classical, text-based language, contemporary writing of all qualities, in forms of art such as musicals or theatre whose reference is the visual and the physical.

The key word is flexibility today, a concept which all too often serves as a façade concealing the facts of economic reality. The chances of playing Shakespeare on a regular basis for professional actors are increasingly few and far between. Drama schools, while determined to offer their students the most complete type of training, have naturally the welfare of their students at heart. Realistically, television is now the largest employer and provider of first acting jobs. The tendency - whether openly declared or not - is therefore to lay the emphasis where the opportunities are.

The British press, as you may know, has made much of these issues giving them a social, political value. The trend at the moment is to make teachers and education at large bear the weight of our frustration, it seems. However, is it not also the role of theatres and directors to renew their own interest in the classics (particularly Shakespeare), and therefore offer more opportunities to young actors? With the gradual decline of the network of local repertory theatres, which served as a continuing opportunity to explore theatre work for several generations of actors, I think it is crucial at this moment in time to create and encourage opportunities of working on classical text. We often fall prey to a kind of absurd stubbornness : we air our regrets, denounce vehemently what we consider to be scandalous but, in the end, we refuse to give ourselves the means of realising what we would expect.

As we approach the new millennium - a phrase much used these days - we seem to be overcome by a kind of irrational fear. Will Shakespeare's voice be lost forever because of television? we ask ourselves. But are we really looking at things in the right way? Is not our view of cultural processes slightly misguided ? As Umberto Eco wrote very wisely : «in the history of culture it has never happened that something has simply killed something else. Something has only profoundly changed something else».

It is precisely those changes that we fail to grasp fully. Because of the influence of television, our way of speaking as well as our 
way of listening have changed today. I think it is crucial to be aware of this. We can get fairly close to the way Henry $V$ or Hamlet were staged in Shakespeare's time, we can try also to reconstruct the way the English was spoken. But somehow all these efforts fall short of the real and most important goal : the Elizabethan ear. How did one hear a Shakespeare play, this is the hardest to know. My personal view is that - in spite of many worthy and well-documented books on the matter - we will probably never know for sure : we are, even when we hear a Shakespeare play, bound irrevocably to modernity. The Elizabethan ear was no doubt different from our own, as people were not spoken to, talked to, entertained, in the same way. A modern voice has to engage us in a different way in order to make us truly listen in a society which seems to rely solely on the belief that image is truth, that it is more important to show rather than to tell. And for this voice to engage us, one must experiment relentlessly, always questioning and redefining what we would be tempted to call «that definitive Shakespeare voice» - which is of no value to modern audiences per se.

This brings me to the fascinating area of listening and of being heard. Part of my job consists in answering letters from members of the audience. This is often the time when the modern ear speaks to me in person, as it were ! I give great importance to these letters, they are another way for us of monitoring performances and of knowing our audience. They are always answered and the matter in question is looked into almost immediately.

Some are also quite revealing of common trends. I received a letter only the other day which amongst other things said : «please tell that actor to 'turn it up a bit'». Interesting, isn't it, that this person considers the business of acting as a mere question of putting the volume control up a notch or two. If only every actor was a piece of electronic equipment we could certainly apply this type of criteria, and this would make my job a lot easier, but not as interesting, dare I say!

It's never as simple as telling someone to speak up, often the reason why the actor isn't being heard has little to do with volume per se. However, very often, almost unconsciously, we mean volume when we speak of not hearing this or that actor. We then resort to the word «projection», which somehow sounds right because it has a slight technical ring to it.

The word, I would suggest, is largely misleading. It is useful to know that the word «projection» as applied to a voice is of fairly recent usage. This, in many ways, is particularly interesting as 
projection is primarily a visual metaphor used to describe something which is spoken and has to do with the listener's ear.

Projection calls up immediately the image of a voice which is thrown forward, as if the actor was someone - as is sometimes the case in modern art - who would be literally throwing paint onto a white canvas - to express himself/herself through language. Thus, if by projection we mean only volume, we are then, as Hamlet would have it, making no difference whatsoever between actor and «town crier».

I take this current use of the word «projection» as indicative of the way language functions in our visual society. Faced with a complex many-faceted phenomenon we resort, as modern speakers/listeners, to an image which is the closest to our habitual ways of perceiving the world. Admittedly, we are now creatures for whom sight is, on the whole, dominant, and the world we have created for ourselves is visual.

But are we not missing something if we use a visual metaphor to express an oral phenomenon which involves both the voice and the ear? Let's not forget that for the Elizabethans projection probably only evoked two things : the mechanical act of projecting an object, or the alchemic transmutation of metals into gold or silver.

We also say that a speech, or an entire Shakespeare play sometimes is not well-spoken, is not up to standards. What do we mean by that? Evidently, there are a certain number of basic rules which any actor has to know when working on classical text. These, in most cases are known, but there is then the question of the choice which the actor makes when speaking: and I am certainly not denying that some of these choices can be more relevant than others.

However, a sound is not a sound without somebody to lend an ear to it, rhetoric is nothing without an audience. There are a certain number of factors which affect the receiver's ear. These can be cultural factors such as the transition between different acting styles or the level of training which our contemporary ear has had.

There are also personal, emotional factors. Perhaps, often we feel the performance was not well-spoken because, somehow, it did not live up to our expectations of how we think it should be performed. Is it that many of us have a self-conscious model, perhaps our own first experience of Shakespeare that meant something to us and becomes our reference point for the future (some treasured performance, kept under glass)? Nothing from then 
on can quite compare with that experience.

But most of the time it is more complex than nostalgia. Take for example the thorny area of accent : I must confess that I have a file full of letters, a lot from America, explaining how the incomprehensible British accents put one more layer between these people and understanding. I only mention America because, from a country and culture with an even richer variety of speech tunes than my country, one would expect perhaps a greater tolerance towards accent. But surprisingly, what is expected is a type of English deprived of its natural colour and verging on Received Pronunciation.

I remind myself constantly that audibility is not embedded in Received Pronunciation. The familiarity which those in power have with speech and the articulate confidence gained from coming from the right quarters, and many other points I could bring up, can lead us all to hear these types of voices as out-shining all others. But, to my mind, the role of theatre is at least to question these assumptions so that we do not simply perpetuate those givens but work towards a broader tolerance.

Every speech pattern (i.e., accent, rhythm) is capable of audibility, each speech pattern has its own music, each speech pattern is not an accent until it's compared to other accents. The point that makes every speech pattern audible is the dynamic of the physical making of those sounds. The speaker must have the desire to get through to a listener and must be confident that every speech pattern has a right to be heard.

There is no policy at the RST that says that actors have to adopt Received Pronunciation. So for me, when I work with actors, it's always a question of finding the way for each person to be articulate, not - of course - that articulation is solved for all that if we all speak in a particular accent.

And, in the end, surely, what we all want is good acting, not just good speaking. Good acting that convinces, persuades, and where the speaking is a part of this whole. This is where the voice coach may come in, for - as Adrian Noble himself once remarked - «a good voice teacher is a good acting teacher». Good speaking also implies good listening, being actively engaged in a performance. Obviously, to hear an actor you have to be concentrating on the actor who is speaking.

Sometimes for a multitude of different reasons, that actor's preoccupation with his way of acting, the stage picture created at that moment, a lighting effect, anything that pulls the audience 
away from the actor speaking can contribute to our being unable to follow the performance text, and may therefore leave us feeling we cannot hear, that the text is not well-spoken, even if that same actor was standing still, with one spot-light on him or her speaking at the same volume.

The balcony in the RST is not vocally difficult to reach, in spite of what one might think. Having said that, the main difficulty with the balcony is insuring that action and audience are kept together during the show, the distance between the two being great. We are so used to conversing close-up to each other and we so often have an easy comfortable view of the person vocalising to us, on television, in films, that it is increasingly hard to maintain the same relationship, when the person speaking is a small figure a long way away.

As for the performers themselves, they must be aware naturally that different voices have different characteristics and therefore different carrying qualities acoustically. The ringing forward resonance (a vibrant tone that rings like a bell) associated with classical singing may assist that vocal quality, and carry better than someone else's chesty tones. But quality of sound does not mean I can hear the word, which is probably why voice work began to depart from a classical singing approach. What voice work strives to do today at the RST is to find an approach that connects with today's acting styles, traditions, sensibilities, enabling those words to live!

\section{Uses of practicality : rediscovering meaning by speaking out aloud}

Now let me enter into the core of my belief about the function of the voice coach in theatre - in other words, how he or she may help that actor to define a Shakespeare voice that is appropriate and speaks to a modern audience. The core, for me, is that it is important to keep voice work practical. But what do I mean by practical ?

Practical work - let's face it - is usually slightly looked down upon, outside of the theatre world. «Practical» stands for not elevated, too experimental, not scientific, intellectually frustrating - a waste of time and energy! And yet I would argue that this type of work has many all-important functions. I would even say that everything about theatre revolves around practicality.

Plays themselves are not simply literary events - they demand interpreters in the deepest sense of the word, and the language of Shakespeare requires, therefore, not a vocal demonstration of writing 
techniques but an imaginative response to that writing. The key word here is imagination, the task of the voice coach being to offer relevant choices to the actor so that this actor's imagination is titillated, excited by the language, which he or she can then share with an audience, playing on that audience's imagination.

If one seeks only intellectual pleasure out of the theatre, fine, I can respect that. However, I would suggest that one is at the same time choosing to discard the very experience of theatre. The ultimate crime - which happily fewer and fewer people commit these days ! - is to believe that the words are there on the page almost ready to be spoken, as if these were already thoughts simply to be brought home by the actor. I believe no writer or poet would be ready to concede that their thoughts came first and short-circuited the organic process of experimenting practically with words.

I was working with a company in Vancouver and at the end of the week's rehearsals - after having explored our voices and opened out different pieces of text to hear the possibilities of the rhythm, to feel how the metre affects the thinking and feeling, looked at structure and form - one of the actors said that as well as being an actor he was also a writer of soap operas and that I had completely changed his way of writing.

Do you think Coronation Street would work in rhyming couplets?! Somehow this seems difficult to imagine! But, seriously, the writer's comments set me thinking at the time. As we are constantly trying to find ways of exploring the acting process, of opening out actors' connection with language that isn't their own, I started thinking it would be a good idea to involve writers and actors in some practical work on language. After talking to Cicely Berry and Colin Chambers (the then RSC Literary Adviser) we put together a group of writers who were interested in taking part and some actors. It was a fascinating experience all round, and broke down barriers and misconceptions.

The actors discovered, for instance, that a writer is not coming from a very different place to them in their creative search, that an idea, an image may result from a struggle to define a gut feeling and not from some crafted well formed idea in the head. The physical connection of language to the body was reaffirmed. After working on Yeat's poem Easter 1916, Ann Devlin changed the title of the play she was writing to After Easter. Such practical exchanges through voice and language work feed, stimulate the company and go beyond merely making sure the actors' voices are technically sound.

It is of course no different when we work on a Shakespeare 
play. A similar physical connection with the language is crucial. Shakespeare, in many ways, is crafted instinct. It is thus our task to find what the best way to tap into someone's imagination is. The moment when actors are no longer heard is when the emotions which get their own imagination going are stilted, rigid, and fall sadly short of the dramatist's imagination. As Peter Brook put it : «People... forget that a text is dumb. To make it speak, one must create a communication machine. A living network, like a nervous system, must be made if a text which comes from far away is to touch the sensibility of the present».

This journey is never to be taken for granted. It is a process which every text must undergo every time it is staged. There is no definitive rehearsal that would solve the problems and indicate the ways of staging a given play. Again, this is perhaps where creative, practical work on voice can help forge new meaning by offering areas of exploration and challenge. I suppose, implicitly, the central area behind voice work at the RSC comes back to posing the question «Does meaning change by speaking out aloud ?». It would be unwise to jump hastily to the end of the process for, as Peter Brook says, «a word does not start as a word»: «Shakespeare's words are records of the words that he wanted spoken, words issuing as sounds from people's mouths, with pitch, pause, rhythm and gesture as part of their meaning. A word does not start as a word it is an end product which begins as an impulse, stimulated by attitude and behaviour which dictates the need for expression» ${ }^{7}$.

Something happens when we vocalise, when we isolate sounds, when we start to speak words aloud and when they are put to the test of our physicality, of our anatomy. We expose ourselves in a way that makes taking that language back more difficult. Our body begins a debate with itself, becomes alive with the vibrations of sound produced in the mouth or rooted deep in the muscles which aim at defining sound. In fact, the spoken words bring into play all the senses, before sense and another level of meaning are reached.

«How do I know what I think until I hear what I say», as Oscar Wilde once said. A concrete illustration of this phrase was reported to me when I was leading a workshop recently: a grandmother said that the work we had done that day and what I was talking about reminded her of what her 6 year old grandson had said to his mother while they were driving through Wales: «Look, mummy, sheep ! Sheep ! Sheep !» - «you don't have to keep telling us», the mother replied - but the boy said : «how do I know they're there, if I don't tell you !?». 
Therefore, when we speak of ideas, of sense, we slightly take for granted those physical processes which affect a word and change its meaning. We tend to separate something which is an organic whole. In doing so, we become blind to the fact that it is precisely this physical connection to the words which enables the actors to make that language theirs.

The struggle for meaning is not just impressionistic theatre mystique, it is an indispensable aspect of the rehearsal process and carries on during the life of every production. In this struggle, practical work on poetry is useful and may help both to spark creativity and shed some light on the way meaning is born into language. After a performance of More Words, a show that Cicely Berry and I directed, Katie Mitchell (former Artistic Director of The Other Place in Stratford) gave me an essay by Ted Hughes, because of its echoes with the piece. In it, Ted Hughes compares the writing of a poem - the coming into existence of words - to the capture of a wild animal. You will notice that in the following passage Hughes talks of «spirit», «living parts», but never of «thought» or «sense». With great care and precaution, he advises : «It is better to call it [the poem] an assembly of living parts moved by a single spirit. The living parts are the words, the images, the rhythms. The spirit is the life which inhabits them when they all work together. It is impossible to say which comes first, parts or spirit».

There is also true life in words, as many are connected directly to one or several of our senses. Here Hughes talks revealingly of «the five senses», of «word», «action», and muscle, all the things which a practical approach to language is more likely to allow one to perceive and do justice to:

Words that live are those which we hear, like «click» or «chuckle», or which we see, like «freckled» or «veined», or which we taste, like «vinegar» or «sugar», or touch, like «prickle» or «oily», or smell, like «tar» or «onion»: words which belong to one of the five senses. Or words which act and seem to use their muscles, like «flick» or «balance». ${ }^{8}$

In this way, voice work lends itself rather well, I think, to what Adrian Noble calls «a theatre of poetry», a form of art which rooted deeply in its classical origins - would seek to awaken the imagination of its audiences through love and respect for words, satisfying at the same time our eternal craving for myths and twice- 
told tales.

This can only be achieved at some cost : there is indeed a difficult battle to fight (and win !): «the battle of the word to survive». This phrase was coined by Michael Redgrave at the beginning of the 1950 s, in a period when theatre began to be deeply influenced by more physical forms of art such as mime ${ }^{9}$. Although the context is obviously different, the fight today is of the same nature.

\section{$* \quad * \quad *$}

If - by way of concluding this paper - I look for a moment to the future of voice work in theatre, I think I am able to say with some degree of certainty that the demand for this type of work will in fact be greater in years to come because of the way actors are trained today and because of the current climate in the world of theatre. Increasingly, directors want to incorporate voice work as they are often curious to learn more about a perspective which for them has ceased to be common knowledge. This climate has created a situation in which the voice coach has a greater sense of being included, of being part of a team. I believe this is something positive for theatre. What theatre seems to be lacking at the moment, however, is the philosophical attitude to finding the way forward for actors today, in an artistic world where expectations have become vastly different, and where the new value system somewhat discourages practice and exploration. The present voice team needs, continually, to find ways to excite actors with Shakespeare, to demystify approaches to classical text, and to help those actors experience the value of regular work - but, above all, it has to be by working with directors who are passionate about Shakespeare and with a vision of language work, because in the end it is they who set the agenda for what voice work can be in theatre.

Through working at the RSC I have been fortunate to have been given the opportunity to discover through doing. My journey has indeed been one of practical discovery. Voice work for voice work's sake is not enough in theatre : the work has to fulfil a deeper and ultimately more important role. I must believe that what I have to offer to actors is a vision of acting - not just a method of speaking better - a vision of acting which is about us as human beings. This is why, in the end, I smile professionally when someone says to me, «I could hear every word of that play», but inside, I sink : if this is the ultimate result of the work, it means that I have failed in some 
way. I, of course, would argue - as I hope this paper has shown that there is greater profit to be gained from voice work, and I pray the RSC will continue to believe that voice has a practical role to play.

On a more personal note, I am often reminded how much, as an individual, I owe to Shakespeare's spoken word. The rather quiet and inarticulate schoolboy I once was found in the speaking, the acting of those words, a means to quench his thirst for expression. I would like to close on a few lines which I cannot help but make my own whenever I speak them. These are taken from a poem by the Welsh poet Gillian Clarke :

My head is full of sound, remembered speech, Syllables, ideas just out of reach ;

The close, looped sound of curlew and the far

Subsidiary roar, cadences shaped

By the long coast of the peninsular,

The continuous pentameter of the sea.

When I was ten, a fool and a king sang

Rhymes about sorrow, and there I heard

That nothing is until it has a word.

Andrew WADE

Head of voice

Royal Shakespeare Theatre

\section{N O T E S}

${ }^{1}$ Peter Hall, «Avoiding a Method», Crucial Years, Stratford-upon-Avon \& London, Reinhardt, 1963, p. 19.

${ }^{2}$ Peter Brook, «What about real life ?», Crucial Years, Stratford-uponAvon \& London, Reinhardt, 1963, p. 21.

${ }^{3}$ Unpublished letter.

${ }^{4}$ Both quotations are taken from The Stratford-upon-Avon Herald, Friday 5th August 1960.

${ }^{5}$ Unpublished letter.

${ }^{6}$ Quoted in Stephen Fay, «Waking from the Dream», The Independent 
Voice work at the Royal Shakespeare Company

on Sunday, 17th March 1991, p. 12.

${ }^{7}$ Peter Brook, The Empty Space, Harmondsworth, Penguin, 1968, p. 15.

${ }^{8}$ Ted Hughes, Winter Pollen, London, Faber, 1994, p. 12.

${ }^{9}$ Michael Redgrave, The Actor's Ways and Means, London, Heinemann, 1953 , p. 67. 